\title{
Research on the Developing Approach of Digital Humanities in the Field of Library Science in China
}

\author{
Panpan $\mathrm{He}^{*}$ and Ya Chen \\ Dept. of Information Management, Nanjing University ,China \\ ${ }^{*}$ Corresponding author
}

\begin{abstract}
Under the tide of digital humanities, the Library actively participates in the research and practice. It has made considerable achievements. Based on the research documents collected by the CNKI and WOS database, this research reviews digital humanities in the field of Library Science. This article attempts to analyze the hot spots and development trends in order to gain a deeper understanding of research results and forecast the future research direction. The basic issues of digital humanities, library resources construction, library services and scientific research support. According to the analysis and discussion of the research and practice, the key points can be concluded to three parts, they are collaborative communication during country and domain, create good digital humanities atmosphere, carry out the research in an innovative way.
\end{abstract}

Keywords-library; digital humanities; developing approach; hotpot analysis

\section{INTRODUCTION}

Since the concept of "Digital Humanities" was proposed in 2001, it has attracted much attention from humanities researchers. Statistics showed that over 180 research institutes, technology centers named are running. Many humanities scholars also carry out the project ${ }^{[1]}$. With the rapid development of information technology, Digital Humanities, with the characteristics of its cross - disciplinary and cross field, which has break through its barriers and boundaries of subject, profoundly influenced literature, archaeology and other fields. Now it has became a powerful complement and strong power of traditional humanities research. For its academic and application value, it can be summarized into 4 parts: save the time and energy of traditional humanities scholars in text processing, find information, calculation; the introduction of new methods and tools to solve the problem of traditional humanities; use digital tools or way of thinking to put forward new questions in humanities; use digital thinking to creatively destroy and build the traditional humanities field ${ }^{[2]}$.

Under the background of "Digital Humanities", it naturally touches upon the field of library science and brings it with new opportunities. Digital humanities in the field of Library Science, which is that the Library attempts to explore the question of digital humanities from its perspective, and attempts to promote, participate in and dominate the research and practice. Since the 1990s, compared with China, the study of digital humanities in the field of libraries has been mainly focused on countries like Europe and the United States ${ }^{[3]}$. How to participate in research and practice has become a topic that scholars urgently need to solve. In recent years, the research topic are the introduction of digital humanities, the role orientation, the relationship between digital humanities and libraries. However, there is still a lack of in-depth discussion on the research and practice of from the perspective of metrology ${ }^{[4]}$. This article attempts to sort out the way of development of Digital Humanities, analyze the hot spots and development trends in order to gain a deeper understanding of their research results and forecast the future research direction.

\section{THE DATA SOURCE}

Based on the words digital humanities,and humanities computing, digital humanities, humanities computing as the subject, it retrieves the relevant literature from the Chinese Science citation database and CNKI, which limited field of Information Science and Library Science, until November 13, 2017, it has got about 140 foreign documents and 116 Chinese literature. About the research method, this article mainly choose the literature analysis method to analyze the various aspects of the digital humanities research literature.

TABLE I. THE AGE OF LITERATURE PUBLISHED IN THE LIBRARY OF DIGITAL HUMANITIES AT HOME AND ABROAD

\section{Literature volume}

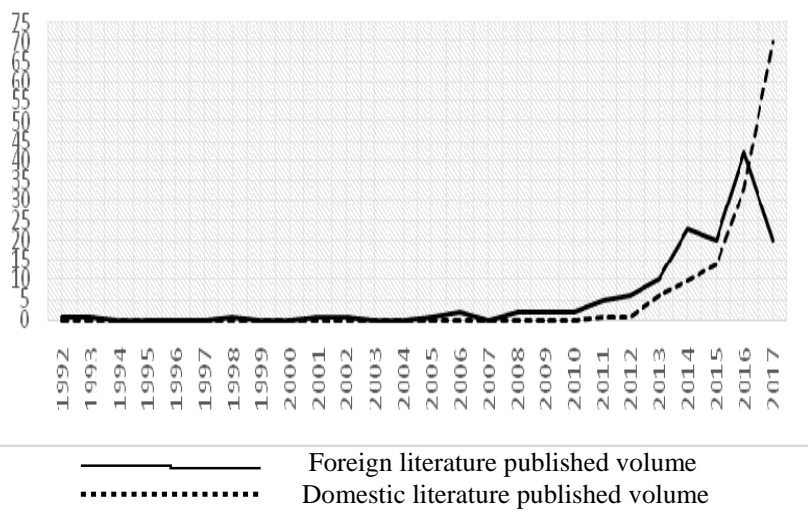

III. ANALYSIS ON THE APPROACH OF THE DEVELOPMENT OF DigITAL HUMANITIES IN THE FIELD OF LIBRARY

Since the 1990s, the research has been mainly focused on countries like Europe and the United States, while China has generally started in 2011. Therefore, in order to analyze the 
research literature comparatively and explore its research process, the article lists foreign literature accordingly. As an emerging field, from research papers and topics, we can analyze the development path of digital humanities.

In Library Science, the literatures have fluctuated over 20 years, but it was still on the rise in the whole. The 2010s was an important turning point. The number was in a slow growth trend before 2010s, but it began to grow rapidly after 2010s. Comparatively, its research is at the initial stage at 2011s, it began to grow rapidly after 2012s. Thus, after 2012, the academic community began to try to support and participate in research and practice in various forms.

The development trend can be divided into 3 stages: the early embryonic stage (2011-2012 years), the attention of this stage is not high. It was not until 2011s that the literature appeared. In the initial stage (2013-2015 years), the research literature has been growing slowly and the annual literature amount has been kept in 5-15. The high-speed development stage (after 2016), In 2016, Peking University library launched the series of Digital Humanities activities and invited Digital Humanities Scholars to give special lectures, so the 2016 academic paper "blowout" appeared.

\section{A. Research Topic Word Frequency Distribution}

Through the analysis of key words and word frequency, the theme distribution of research in China can be grasps. A total of 351 key words are obtained in this study. In highfrequency keyword, user information behavior, related data, librarians, digital humanities construction, big data, digital library, subject service, text mining, knowledge service and other key words appear. Among them, the digital library reflects the research object of Digital Humanities and the keywords about related data, text mining and Natural Language Processing describe the research technology and methods of Digital Humanities.

\section{TABLE II. DOMESTIC LIBRARY DIGITAL HUMANITIES RESEARCH HIGH FREQUENCY KEYWORDS (FREQUENCY >2)}

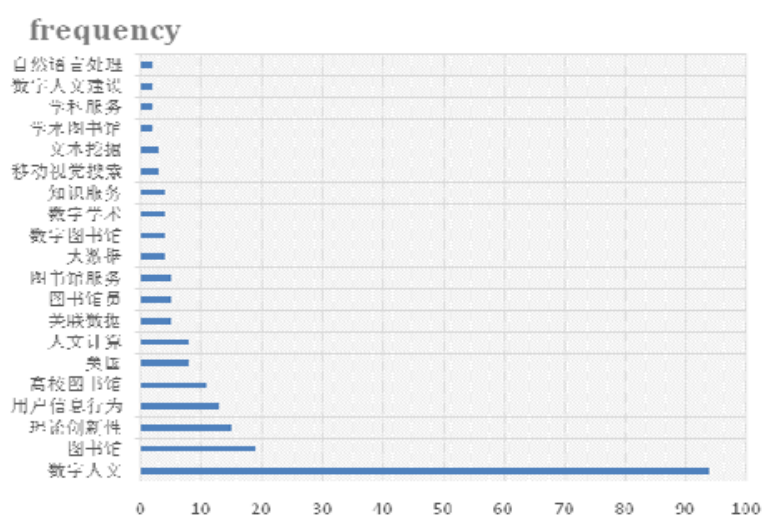

Through the Co-occurrence of time zone images by highfrequency keywords, we can understand the change and development of theme. The key high-frequency words that appeared were digital humanities, librarians, natural language processing, knowledge services and resource construction. The digitization shows that our libraries focus on problem-based research. In the subsequent start-up period (2013-2015), research emerged with keywords such as text mining, academic libraries, open access, big data, data management, data warehousing and more, which pay more attention on data organization and processing. In recent years (after 2016s), the key words are user information behavior, library service, research support and subject service in this field, which indicates that our country begins to pay attention to the application and influence of research.

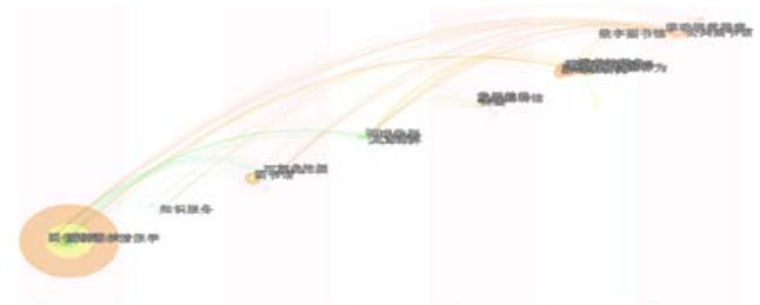

FIGURE I. DIGITAL HUMANITIES LITERATURE HIGH FREQUENCY KEYWORDS CO-OCCURRENCE TIME ZONE VIEW

\section{Digital Humanities Research Hot SPOT AND CORRELATION ANALYSIS}

The analysis of keyword clustering can reflect the hot issues in the field of Digital Humanities. Using CitespaceV to draw the key word common map of the Digital Humanities and select the clustering function, 30 key words co-occurrence clustering are generated, which can reflect the research direction of Library's Digital Humanities field in label 3. We can classify these keywords into 3 themes: Digital Humanities foundation research, library resources construction, library service and research support.

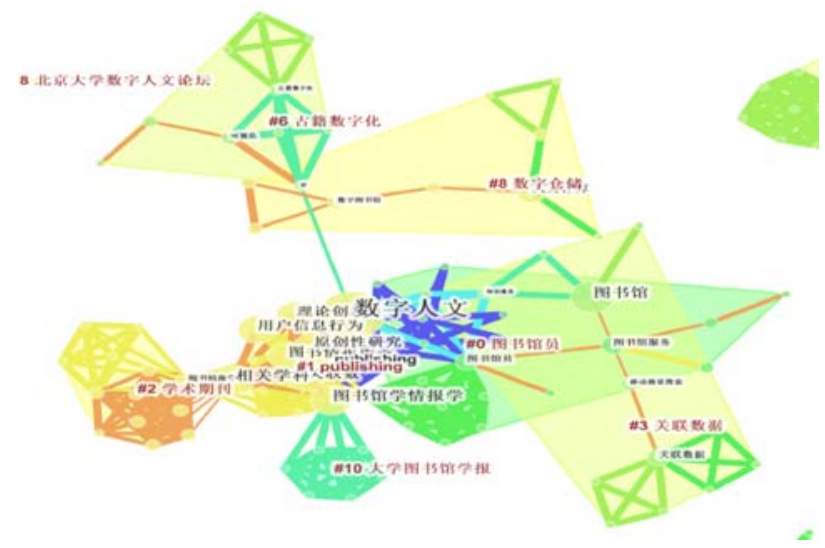

FIGURE II. LIBRARY DIGITAL HUMANITIES LITERATURE COOCCURRENCE CLUSTERING MAP

\section{A. Research on Basic Problems}

The Digital Humanities originated from the practice and basic problems were naturally in open discussion . In order to grasp the relationship between the digital technology and the humanities and social sciences ${ }^{[5]}$, Guang Yang explored the 
ontology of the object of ,it involves the mining, organization, development and analysis of resources. In order to understand it deeply, we must understand the basic theory about technology and standard, technology foundation ${ }^{[6]}$. Wei Liu and Ying Ye thought that the way of technology system and theoretical structure showing the interdisciplinary and crossborder integration, which mainly including digital technology, visualization technology and theoretical results related to structured data, humanities, or computing the visual image or humanities, intelligence or extended applications covering knowledge reconstruction and enhancement technology etc ${ }^{[7]}$. Xuefang Zhu put forward the concept of digital human storage, which is the technological basis for the realization of projects and the way of application. The framework of human entity definition, domain ontology modeling, humanities entity digitalization acquisition and multi-dimensional aggregation service are constructed ${ }^{[8]}$. Lijun Ma thought that the future development is influenced by the Digital Humanities and the library service is changing to the 3 modes of embedded subject service, integrated knowledge service and data analysis service $^{[9]}$.

\section{B. The Construction of Library Resources}

I) the construction of resources : As a document resource management center, library can make use of its own resources and technical advantages to actively invest in the practice of Digital Humanities. Guang Yang thinks that library resources are becoming digitalized, but traditional resources rarely touch deep level applications. In order to guarantee the application of resources exploration, organization and development, we must integrate resources ${ }^{[10]}$.

II) infrastructure construction :A good infrastructure, that is, an internal and external balanced human digital ecosystem, played an important role in the sustainable development of technical and humanistic research. Wei Liu and Rong Xie thought that the infrastructure construction based on support activities should have all the documents, data, related software tools, academic exchanges and public facilities and related services in the world. They advocated to work at the national macro level and followed certain technical standards, norms and agreements ${ }^{[11]}$.

III) Librarian construction: The digital humanistic practice has put forward new requirements for librarians. Jie Li put forward that in order to realize the role transformation of librarians, we need to learn and explore from 5 aspects: data manager, resource discovery and integrator, interdisciplinary knowledge transmitter, content disseminator and promoter, and infrastructure builder ${ }^{[12]}$.Huan Ling believed that librarians should have the ability to guide readers to read humanities books, interact with readers fully and analyze information according to readers' requirements ${ }^{[13]}$.

\section{Library Service and Scientific Research Support}

I) Digital Humanities is an interdisciplinary scientific research and practice activity which is intersected by digital technology and humanistic exploration. Xiaoying Ceng pointed out that The library have the functions of achievement dissemination and knowledge popularization, project support and auxiliary functions, provide embedded subject services, data analysis services, results operation and application functions", she appeal for new growth points of their services $^{[14]}$.Yongzhong Lai believed that the research and practice of Digital Humanities and the feasibility of logical unity and realistic logic, its research support mainly includes 8 aspects: Digital Humanities, scientific research and guidance services, resource acquisition and push, research data management, research support tools, research space, academic communication and publication, scientific research influence evaluation and scientific research personnel education ${ }^{[15]}$. Digital Humanities is the inevitable trend after the construction of digital library to a certain scale. the function and methods of related data technology in Digital Humanities Research are presented in detail, and the digital humanistic service for knowledge discovery ${ }^{[16]}$.

II) It can be seen that the humanities research under the background of "Digital Humanities" presents the characteristics of digitalized research objects, multidisciplinary research teams, intelligent research methods and diversified research paradigms. It is necessary to construct the new connotation of library knowledge service and to inject new research connotation into the work of Library and information and provide a new opportunity for the library's knowledge service ${ }^{[17]}$. In addition, the library has the function of communication in the field of Digital Humanities. In order to strengthen the library culture function and influence, we can introduce the concept and technology of Digital Humanities from three aspects, they are introducing the concept and technology of Digital Humanities, expanding the dissemination service of Digital Humanities, providing data management services, deepening the level of information services, carrying forward the humanities reading and innovating the classic reading promotion service mode ${ }^{[18]}$.

\section{ReaEARCh And Practice Analysis of Digital HUMANITIES}

\section{A. Development Stage Analysis}

For the new field of Digital Humanities, the domestic library circles are still in the exploration stage in theory and practice, but the results are considerable. From the content of this paper, the related theoretical research has discussed the role of Library in Digital Humanities [19], Digital Humanities technology and theoretical structure, service mode and other issues, which provided theoretical and method support for its research and practice. At the same time, it explored the way of The Library to participate in Digital Humanities in practice, including the establishment of Digital Humanities Center, recruitment of Digital Humanities librarians, infrastructure construction, research support services and project support ${ }^{[20]}$.

\section{B. Characteristics Analysis of Research}

From the view of the research practice, the following characteristics are mainly presented. The first characteristic is extensive research topics, which covers the history and the ancient discipline service, mining, culture, Huizhou studies, Genealogy Research etc. It involves not only traditional humanities materials, but also Digital Humanities materials. 
The original digital data is also included in the research area, and the introduction of digital technology is also emphasized. The second characteristic is intelligence research process, using the latest digital and data related technologies to intelligently process, collect and retrieve data, help quickly sort out, locate and grasp the theme and spy the core meaning of the discipline context, save time and cost of research. The second characteristic is the synergy of research methods, which focuses on the combination of humanistic research and computational tools, makes the textual research appear in the form of data. Interdisciplinary collaboration and innovation enable humanities scholars to understand and value digital technologies and methodological tools, and promote natural science scholars familiar with the humanities research objects and ideas ${ }^{[21]}$.

\section{Research Defect Analysis}

The digital humanities research in The Library started relatively later, and the study atmosphere is not strong. The research depth and level only stay at the simple level of service and support. Most scholars have not enough understanding of digital humanities. The corresponding concepts, connotation and denotation and other basic theoretical issues have not yet reached an agreement. At the same time, the lack of more professional digital technologies and methods to support research that the foundation of later research is not strong. Libraries regularly handle structured resources such as textual historical materials, lack of research on unstructured data ${ }^{[22]}$. In addition to technical and literacy training, some humanities researchers lack of digital thinking, less contact with some research methods and skills such as analysis and interpretation of relevant data, and have certain deviations from the overall study. In addition, domestic scholars may encounter issues like resource fragmentation, data access and limited openness in the research process. To a certain extent, it blocked the exchange of resources and academic cooperation in the field of interaction. Thus, we should break through the limitations of the supportive service model and structured resources. Facing with the full integration of humanities research process, it use digital technology to participate in digital humanities practice with interdisciplinary thinking and perspective in order to effectively promote effectively promote the humanities research and development ${ }^{[23]}$.

\section{The Key Points of Digital Humanities Development in Chinese Library}

I ) Cross-border Transnational Exchange and Collaborative Research : Chinese scholars should actively participate in digital humanities projects, alliances and conferences of international libraries, communicate effectively and share experiences. As far as possible to participate in the construction of foreign projects, and invited foreign experts to help skills and project management experience training. The Library introduced foreign cases of achievement for analysis and research, combined with the actual situation of China to form best practices. For example, they can cooperate with blogs and online publishing platforms to introduce specialized equipment, tools and software, provide digital publishing services for digital humanities and enhance their usability by extending services. The Library should realize open strategy. and actively cooperate with universities, research centers, national digital infrastructure and other organizations and institutions, and customize personalized digital humanities services according to the needs of service objects. With the subjects of computer linguistics, history and geography, social sciences, publishing to build digital humanities collaborative research center. After reaching a certain scale, the Digital Humanities Center Alliance can be formed. From the standpoint of its own subject, the Library have to break through the limitations of natural social sciences, humanities and application projects. Comprehensively combine research methods and approaches in other disciplines to research and realize the maximization of resources at the research level, the maximum generalization of analytical methods and the maximum knowledge contents ${ }^{[24]}$.

II) Good digital humanistic atmosphere to create: It can create good digital humanistic atmosphere from the national policies, libraries and other parts. The country formulate a development plan, set up a digital humanistic fund, encourage the establishment of library-centered exchange and share platform to attract humanities scholars in various fields. And the country can also build learning communities to encourage teachers and scholars to conduct academic exchanges and mutual assistance. In order to consolidate the data foundation of digital humanities research and realize the data acquisition and opening up, the Library need to improve its own reserve of resources, construct a collection resource system and open up the existing database and corpus resources with low utilization rate. Set up digital humanities exchange platform and alliance to share the cost of purchasing resources or to exchange views on the process and achievements of open project construction. The library should nurture digital humanities librarians and actively popularize digital humanities and provide consulting services based on their own properties of intermediary and academic. It provides digital humanities researchers with professional knowledge and techniques Training, improve digital humanities. Establish and improve the guarantee mechanism and promote the guiding and normative system and mechanism, the synergistic relationship mechanism of exchange and cooperation, the management mechanism of scientific planning and efficient governance, the marketing mechanism to enhance the recognition and brand value, the evaluation mechanism of quality and benefit and other aspects of innovation. The library can collect and sort out the humanities research database, tool software or platform information from around the world, and discuss the release of relevant news and information to facilitate more users' attention.

III) Digital Humanities research in an innovative way: Encourage, advocate and mobilize the participation of the whole society, widely absorb social funds, popularize digital humanities knowledge and achievements, and promote digital humanities research and practice. Drawing on the experience of foreign foundations, establishing a digital humane project funding system can attract privately funded digital humanities projects. In addition to being funded by the National Natural Science Fund. The Humanities and Social Science Fund can 
be included Encourage universities and research institutes, private enterprises and enterprises to join the research team, including those with market prospects related to economic and social development, also encourage enterprises and private parties to participate in and promote the development toward the market and industrialization. In cooperation with publishers, media companies, etc, they may entrust part of the publicity, dissemination and promotion of digital humanities and research results. Collaborate with bookstores and business organizations to create a digital laboratory that integrates learning, creative products, shared bookstores, cinemas, galleries, music, photography and other creative digital spaces to create amateurs and humanities scholars to draw the public's understanding. Pay attention to and participate in the practice, carry out projects in a multi-dimensional way of thinking. In cooperation with data providers, outsourced data vendors are commissioned to carry out data analysis. However, in the outsourcing cooperation, The library need to be involved in the supervision of data management and project processes to gradually accumulate and summarize project implementation and management experience. Draw on the experience of big data processing, refer to the editing and publishing departments or data analysis companies for processing results of non-written materials, digging and developing interdisciplinary thinking and perspectives, and processing unstructured data.

\section{CONCLUSION}

Although the development of digital humanities has brought opportunities to the library, it has even brought challenges. Although the current digital library humanities research is still in the exploratory stage, as long as preparations are made and its advantages are taken advantage of, breakthroughs in auxiliary supportive services Restrictions, to take the leading position in innovative digital art research and practice, to promote cross-border exchanges and cooperation, to create a good digital humanistic atmosphere, the library can continue to promote its digital humanities to further and further development.

\section{ACKNOWLEDGMENT}

The preferred spelling of the word "acknowledgment" in America is without an "e" after the "g". Avoid the stilted expression, "One of us (R. B. G.) thanks ...." Instead, try "R. B. G. thanks". Put sponsor acknowledgments in the unnumbered footnote on the first page.

\section{REFERENCES}

[1] Benjun Zhu,Hua Nie. Digital Humanities: The New Direction of Library Practice[J]. Journal of University Library,2017,35(04):23-29

[2] Guang Yang. Research on the Strategy and Appication of Lbrary Resources Integration under the Background of Digital Humanities [J]. Journal of hebei Library,2015,35(10):7-9.

[3] Xiao Guan. Digital Humanities: Concept, Current Situtation and Thinking[R/OL].[2014-11-07]. http: //meeting. lib. szu. edu. cn/conference/zh-hans/infomation? v=07000003.

[4] Wei LIu,Discussion on the Technical System and Theoretical Structure of Digital Humanities [J]. Journal of China Library,2017,43(05):32-41.

[5] Jie Li. Library Conversion under the Background of Digital Humanities [J]. Library Research and Work,2017,(10):26-30+37
[6] Huan Ling. Discussion on Library Reader Service under the Backegrond of Digital Humanities[J].Office Bussiness,2017,(17):159160

[7] Rong Xie,Lei Zhanag,Yongjuan Liu. The Construction of National Data Base for Digital Humanities [J]. Journal of China Library,2016,42(05):29-39

[8] Xiaoying Ceng. Library on the Background of Digital Humanities :Role and Service[J]. Books and Intelligence,2014,(04):111-113

[9] Benjun Zhu,Hua Nie. Cross-border and integration: Digital Humanities from a Global Perspective-Summary of the First Digital Humanities Forum[J]. Journal of University Library,2016,34(05):16-21

[10] Cuijuan Xai, Lie Zhang. Application of Relevance Data in Genealogical Digital Humanities [J]. Library Magazine,2016,35(10):26-34

[11] Ernesto Priani Saiso. Finding support for disruption: developinga digital humanities project in Mexico [J]. Aslib Proceedings, 2012, 64 (1): 97103

[12] Buddenbohm S, Matoni M, Schmunk S, Thiel Carsten .Quality Assessment for the Sustainable Provision of Software Components and Digital Research Infrastructures for the Arts and Humanities[J].bibliothek forschung und praxis,2017(41):231-241

[13] SoringS.Technical and Infrastructural Solutions for Digital Scholarly Editions: DARIAH-DE and TextGrid[J] bibliothek forschung und paraxis.2016(40)207-212

[14] https://luc.edu/ctsdh/researchprojects/jesuitlibrariesproject/

[15] ]https://er.educause.edu/articles/2014/6/linked-jazz-building-withlinked-open-data

[16] Leydesdorff L, Salah AAA. Maps on the basis of the Arts \& Humanities Citation Index: The journals Leonardo and Art Journal versus "digital humanities" as a topic[J] journal of the American society for information science and technology,2010(61):787-801

[17] Toms EG, O'Brien HL. Understanding the Information and Communication Technology Needs of the e-Humanist [J] journal of documentation,2008(64)102-103

[18] Xiaoxi Zhang.American College Students set up Digital Humanities Major.Chinese Journal of Social Science, 2016-01-15

[19] PooleAH.The conceptual ecology of digital humanities[J]journal of documentation,2017(73):91-122

[20] Yaoran Zhang,Shaozhen Zhang. Digital Humanities Suevey in American Universities[J].Library Forum,2017,37(03):26-34

[21] Ping Ke,Ping Gong. The Evolution of Digital Humanities and Its Hotspot Analysis[J].Journal of China Library,2016,42(06):13-30

[22] Liheng XU. Why We need Digital Humanities [N]. Social Science Journal,2017-08-24(005)

[23] G. Eason, B. Noble, and I. N. Sneddon, "On certain integrals of Lipschitz-Hankel type involving products of Bessel functions," Phil. Trans. Roy. Soc. London, vol. A247, pp. 529-551, April 1955

[24] LIheng,Xu:Why we need Digital Humanities[J] Society proceedings,2017-08-24(005) 